\title{
Risk factors of delayed surgical evacuation for initially nonoperative acute subdural hematomas following mild head injury
}

\author{
Sachin Baldawa
}

Received: 29 August 2014 / Accepted: 4 September 2014 / Published online: 20 September 2014

(C) Springer-Verlag Wien 2014

Dear Sir,

I read with great interest the article by Kim et al. [1] mentioning the risk factors for delayed surgical evacuation of acute subdural hematoma (SDH) in mild head injury patients who were initially treated by non-surgical means and would like to add a few comments.

In patients with traumatic brain injury, the decision to evacuate acute SDH is based predominantly on the patient's GCS score, pupillary examination, and CT scan findings. The guidelines laid down by the Brain Trauma Foundation in 2006 for the management of acute SDH are universally followed [2]. The Brain Trauma Foundation lays great emphasis on the thickness of acute SDH and the degree of midline shift in guiding surgery for patients with traumatic brain injury [2]. As per the Brain Trauma Foundation guidelines, acute SDH more than $10 \mathrm{~mm}$ thick or a midline shift greater than $5 \mathrm{~mm}$ on imaging, irrespective of the patients GCS score, needs surgical evacuation [2]. However, volume of the hematoma has not been considered as a guiding parameter in patients with acute SDH. In fact, the Brain Trauma Foundation emphasizes calculating the volume of hematoma in order to decide surgical evacuation of extradural hematoma only [2]. Patients with mild head injury (GCS score of 13 to 15) having acute SDH are more likely to have hematoma thickness of less than $10 \mathrm{~mm}$ and midline shift of less than $5 \mathrm{~mm}$ [1]. By calculating the volume of hematoma in patients with mild head injury having acute SDH, neurosurgeons will be able to predict which hematomas are likely to enlarge and hence are likely to need evacuation. In the series published by Mathew et al.
[3], 23 patients with mild head injury having acute SDH were initially subjected to non-operative management. In six of these patients who needed delayed surgical evacuation of the acute SDH, the volume of the hematoma was significantly larger than the group that was managed conservatively [3]. In the authors' series, also the volume of the hematoma was an independent risk factor for the development of delayed hematoma enlargement [1].

The authors need to be commended for re-introducing volume of the hematoma as a decisive parameter in predicting hematoma enlargement apart from thickness of the hematoma and degree of midline shift in patients with acute SDH and good neurological status.

Conflicts of interest None.

\section{References}

1. Kim BJ, Park KJ, Park DH, Lim DJ, Kwon TH, Chung YG, Kang SH (2014) Risk factors of delayed surgical evacuation for initially nonoperative acute subdural hematomas following mild head injury. Acta Neurochir 156:1605-1613

2. Bullock MR, Chesnut R, Ghajar J, Gordon D, Hartl R, Newell DW, Servadei F, Walters BC, Wilberger JE (2006) Surgical management of acute subdural hematomas. Neurosurgery 58(3):S 16-S 24

3. Mathew P, Oluoch-Olunya DL, Condon BR, Bullock R (1993) Acute subdural hematoma in the conscious patient: outcome with initial nonoperative management. Acta Neurochir 121(3-4):100-108

\footnotetext{
S. Baldawa $(\bowtie)$

Department of Neurosurgery, Ashwini Sahakari Rugnalaya Ani

Sanshodhan Kendra Niy, Solapur, Maharashtra, India

e-mail: sachin_baldawa@yahoo.co.in
} 